DOI - https://doi.org/10.5965/2316796309172020137

\title{
Norma Regulamentadora 17: considerações para sua revisão
}

\author{
Regulatory Standard 17: \\ considerations for your review
}

Larissa Maas ${ }^{1}$

Rosane Malvestiti ${ }^{2}$

Eugenio Andrés Diaz Merino ${ }^{3}$

Leila Amaral Gontijo ${ }^{4}$ 


\section{Resumo}

Atualmente, as normas regulamentadoras no Brasil estão passando por ampla revisão. A norma de número 17 (NR-17) refere-se à ergonomia e descreve aspectos que contribuem para proporcionar ambientes de trabalho saudáveis e seguros. Assim, o objetivo deste estudo foi identificar pesquisas que possam embasar alterações necessárias no texto da norma. Para isso, foi realizada revisão bibliográfica para levantar os principais aspectos que estão sendo estudados na área atualmente. Com isso, foi identificado como pontos fortes a existência de uma norma em ergonomia, o uso da metodologia análise ergonômica do trabalho (AET) e parâmetros a serem seguidos, e como principais pontos frágeis a desatualização e falta de normas de referência, a inexistência de indicação do profissional elaborador da AET e a falta de obrigatoriedade da AET.

Palavras-chave: Ergonomia, Legislação Trabalhista, Riscos Ocupacionais

11 Doutoranda em Engenharia, UFSC (larissa.maas@ifc.edu.b)

ISSN: 2316-7963

2 Doutoranda em Engenharia, UFSC (romaiah50@gmail.com)

${ }^{3}$ Doutor em Engenharia, UFSC (eugenio.merino@ufsc.br)

${ }_{4}^{4}$ Doutora em Ergonomia - Université de Pari (gontijo.lei@yahoo.com)

\section{Introdução}

Atualmente, há uma crescente preocupação com a saúde e segurança dos trabalhadores devido os elevados custos humanos e materiais que a gestão incorreta de recursos nesta área proporciona. Com o intuito de ampliar investimentos e modernizar a legislação em segurança do trabalho há uma proposta por parte do governo de revisão das normas regulamentadoras (NR) que regem a área. No Brasil, são 37 NR em vigor, amparadas pela Consolidação das Leis do Trabalho (CLT), e diversas estão em consulta pública para a indicação de itens que devem ser atualizados.

Com objetivo de resguardar os direitos dos trabalhadores, as NR foram criadas para detalhar os itens citados na CLT, cada uma com tema distinto e orientações que as empresas devem cumprir. Entretanto, estudos apontam irregularidades e inconsistências na legislação, com aspectos pouco discutidos que favorecem o surgimento de doenças profissionais e o aumento de acidentes do trabalho (AQUINO, 2015; GONÇALVES; IGUTI, 2006; MIRANDA; DIAS, 2004; SALIBA, 2011).

Com relação às políticas públicas, em novembro de 2011 o governo federal publicou a Política Nacional de Segurança e Saúde no Trabalho com a participação e apreciação dos Ministérios do Trabalho e Emprego, Previdência Social e Saúde. A partir disso foi criado o Plano Nacional de Segurança e Saúde no Trabalho (Plansat) que definiu as ações, os responsáveis e os prazos de execução para cada estratégia que definida na política. A estratégia denominada "3.1 - Articular as Ações Governamentais de Promoção, Proteção, Prevenção, Assistência, Reabilitação e Reparação da Saúde do Trabalhador" incluiu em suas ações a elaboração e revisão das NR de segurança e saúde no trabalho, com prazo permanente para a execução. Em outras palavras, a revisão das normas regulamentadoras do MTE deveriam ocorrer de maneira contínua (BRASIL, 2012). Porém, somente no ano de 2019 ações foram tomadas neste sentido para a atualização da legislação.

A legislação em ergonomia no Brasil é regida pela NR de número 17 (NR-17) com objetivo de contribuir para harmonizar a saúde, segurança e satisfação do trabalhador (IIDA; GUIMARÃES, 2016). Assim, a compreensão da legislação é fundamental para a correta aplicação, uma vez que a adequação dos ambientes de trabalho promove benefícios à saúde dos trabalhadores (KROEMER; GRANDJEAN, 2005).

Aergonomia pode ser dividida em três domínios: física, que se dedica a observação das posturas adotadas pelo trabalhador e o ambiente físico; cognitiva, estuda a carga mental atribuída à atividade de trabalho; e organizacional, que observa a organização do trabalho como jornada de trabalho, remuneração, controles entre outros (IEA, 2000; WISNER, 1994).

O texto da NR-17 foi aprovado em 1990 e teve as últimas alterações em 2018, com aspectos sobre iluminação atualizados. Os itens da NR são: manuseio de materiais, mobiliário dos postos de trabalho, equipamentos, condições ambientais de trabalho, organização do trabalho, anexo 1 (operador de checkout) e anexo 2 (teleatendimento/ telemarketing). Os anexos foram inseridos no ano de 2007.

Certamente, após quase 30 anos é indispensável a adaptação da NR às novas realidades, levando em conta os avanços dos estudos científicos em ergonomia evitando conflitos de informações na aplicação da norma. Reforçando que o Plansat define que as revisões das NR devem ocorrer de maneira contínua (BRASIL, 2012).

A metodologia sugerida na NR é a análise ergonômica do trabalho (AET), que propõe o estudo da situação real do trabalho, sendo o ergonomista o profissional apto 
a realizar o diagnóstico e a intervenção ergonômica (WISNER, 1994).

Os preceitos da ergonomia indicam que os postos de trabalho devem atender aos requisitos básicos de conformidades, conforto, segurança e condições ambientais adequadas para a realização do trabalho, como citado na NR-17 (BRASIL, 1990). Então, diversos fatores devem ser observados para a manutenção do ambiente de trabalho salutar, como as posturas adotadas, as condições ambientais, a organização do trabalho, entre outras.

Os trabalhadores permanecem empenhados na realização de suas atividades durante a jornada de trabalho, assumindo as mais variadas posturas corporais, sendo algumas prejudiciais, como exemplo manusear cargas (IIDA; GUIMARÃES, 2016; MERINO, 1996; MORO, 2000). As posturas assumidas no trabalho são indicadores que facilitam a compreensão da relação tarefa-atividade pois resultam da organização dos postos de trabalho, das máquinas e equipamentos utilizados, ritmo de trabalho, exigências cognitivas, entre outras (ABRAHÃO et al., 2009; LAVILLE, 1977).

A organização do trabalho contempla o estudo da divisão das tarefas, as competências, os turnos, controle do tempo, relações interpessoais e a participação social (IIDA; GUIMARÃES, 2016; MONTMOLLIN; DARSES, 1990). Segundo Wisner (1994) o modo de organização do trabalho pode gerar problemas de saúde pela falta de conhecimento das características da população trabalhadora por parte dos engenheiros e desenhistas. A participação do trabalhador no processo de organização do trabalho contribui para a aceitação e criação de novos modelos organizacionais e, por perceber sua importância no processo, aumenta sua satisfação no trabalho ficando menos sujeito às doenças e acidentes do trabalho (IIDA; GUIMARÃES, 2016).

Alguns valores de referência são citados na NR-17 para contaminantes ambientais como ruído, temperatura, iluminação e vibração, que influenciam diretamente no conforto, segurança e desempenho do trabalhador (IIDA; GUIMARÃES, 2016; LAVILLE, 1977).

A proposta deste artigo foi analisar as pesquisas realizadas recentemente pelo meio acadêmico e confrontá-las com o que preconiza a NR-17, no sentido de identificar inconsistências na norma. Com isso, algumas potencialidades e fragilidades foram identificadas e podem ser atualizadas na próxima revisão.

\section{Procedimentos metodológicos}

Para analisar o contexto da NR-17 buscou-se por elementos da ergonomia que aparecessem recentemente em estudos científicos e que pudessem contribuir para a identificação específica de riscos ocupacionais. No entanto, como a legislação em estudo é válida somente para o Brasil, o critério inicial de inclusão foi de pesquisas realizadas somente neste país.

Efetuou-se uma busca bibliográfica exploratória nas bases de dados Scielo, Bireme Banco de teses e dissertações Capes e Biblioteca Brasileira de Teses e Dissertações (BDTD). As palavras de busca foram selecionadas a partir da base de descritores de ciências da saúde - BVS pois os termos "NR-17" e "Norma regulamentadora 17" não retornaram trabalhos publicados. Então, novos descritores, "ergonomia" e "riscos" foram selecionados para esta pesquisa. A palavra ergonomia se justifica por ser o eixo principal desta pesquisa e riscos, porque a inadequação nas condições de trabalho pode apresentar riscos para o trabalhador. Foram utilizados de forma combinada, "ergonomia" AND "riscos", selecionando-se documentos escritos em português e inglês entre 2012 e 2017.

Foram excluídos os documentos duplicados e indisponíveis na integra. Após, realizou-se a leitura dos resumos retirando-se as seguintes pesquisas: desalinhadas com o tema, revisões bibliográficas, propostas de metodologia ou ferramentas e estudos realizados com estudantes (figura 1).

Figura 1 - Etapas adotadas para a seleção dos documentos

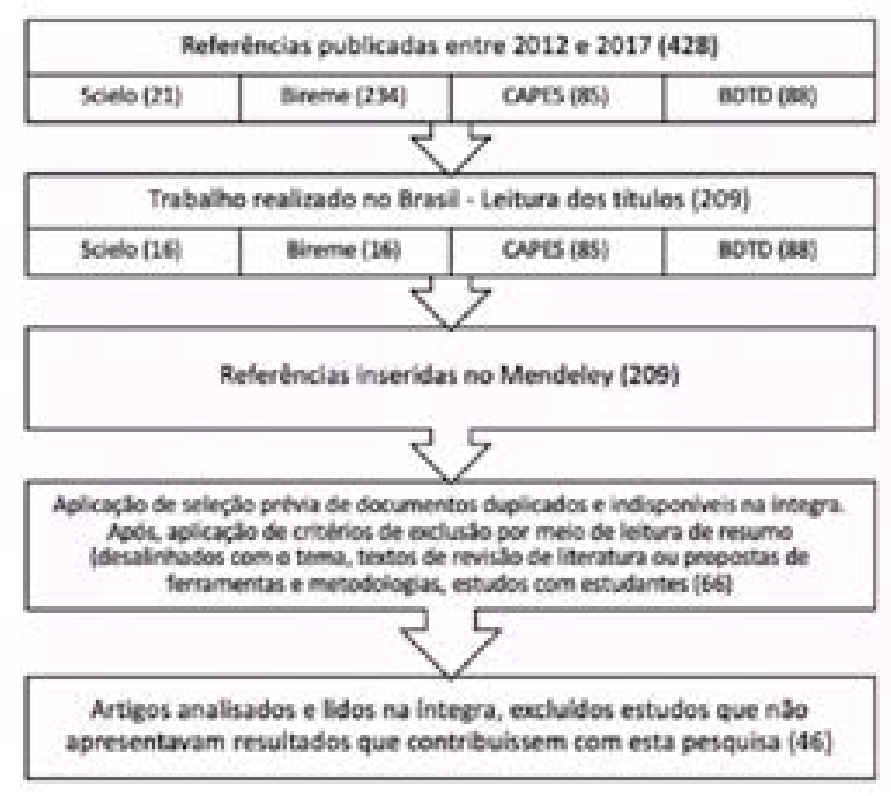

Fonte: elaborado pelos autores

Dos 428 documentos pré-selecionados, 46 foram utilizados na discussão deste artigo. Para a análise, os documentos foram separados, conforme o estudo realizado, nos domínios da ergonomia, sendo ergonomia física, cognitiva e organizacional. Os estudos incluídos na categoria ergonomia física foram aqueles que o objetivo principal do estudo incluiu esforço biomecânico, posturas adotadas, movimento repetitivo, antropometria, mobiliário, esforço físico e condições ambientais. Já para a ergonomia cognitiva os estudos que levaram em consideração a carga mental, atenção, memória e elementos da relação entre o sistema e o indivíduo. A ergonomia organizacional contemplou as relações da organização do trabalho, pausas, dimensionamento de equipes, participação do trabalhador nos processos de trabalho e a relação entre os supervisores e os trabalhadores.

Os trabalhos que utilizaram como metodologia a AET, sugerida na NR17, foram Oliveira (2015), Brito (2015), Rocha e Simonelli (2012), Mendes e colaboradores (2012), Azevedo (2015) e Vilela e colaboradores (2015). Todo o trabalho de seleção e categorização dos documentos foi realizado em abril e maio de 2017.

\section{Resultados}

A partir das pesquisas encontradas, foi detectado os principais aspectos que tem sido levantados no meio acadêmico e que, apesar de conter legislação sobre ergonomia no Brasil, os ambientes de trabalho ainda não estão ergonomicamente adequados.

HFD, v.9, n 17, p. 137-162, junho 2020 
O quadro 1 apresenta, em ordem cronológica, as referências das pesquisas selecionadas para compor esta análise, bem como informações sobre o ano, as categorias de domínio da ergonomia que as pesquisas se propõe a estudar e os principais resultados encontrados.

Quadro 1 - Referência, domínios da ergonomia pesquisado e resultados encontrados nas pesquisas

\begin{tabular}{|c|c|c|c|}
\hline & Referências & $\begin{array}{l}\text { Domínio } \\
\text { pesquisado }\end{array}$ & Resultados encontrados \\
\hline 1 & $\begin{array}{l}\text { ESTEVO, E. Lixo doméstico } \\
\text { produzido em Goiânia: a } \\
\text { exposição e o impacto na } \\
\text { saúde dos coletores. Goiânia, } \\
\text { 2012. Dissertação, Pontifícia } \\
\text { Universidade Católica de } \\
\text { Goiás. }\end{array}$ & $\begin{array}{l}\text { Ergonomia } \\
\text { física e } \\
\text { organizacional }\end{array}$ & $\begin{array}{l}\text { Posturas inadequadas, } \\
\text { ausência de pausas, } \\
\text { deficiências nos processos } \\
\text { de trabalho. }\end{array}$ \\
\hline 2 & $\begin{array}{l}\text { CARVALHO, C. C. S. et al. } \\
\text { Condições ergonômicas dos } \\
\text { trabalhadores em galpões de } \\
\text { frangos de corte durante a } \\
\text { fase de aquecimento. Revista } \\
\text { Brasileira de Engenharia } \\
\text { Agrícola e Ambiental, nov. } \\
\text { 2012. v. 16, n. 11, p. 1243-1251. }\end{array}$ & $\begin{array}{l}\text { Ergonomia } \\
\text { física }\end{array}$ & $\begin{array}{l}\text { Exigências de posturas } \\
\text { inadequadas. }\end{array}$ \\
\hline 3 & $\begin{array}{l}\text { BRITTO, P. C. Análise de } \\
\text { fatores ergonômicos em } \\
\text { atividades de implantação } \\
\text { Florestal. Irati, } 2012 . \\
\text { Dissertação, Universidade } \\
\text { Estadual do Centro-Oeste. }\end{array}$ & $\begin{array}{l}\text { Ergonomia } \\
\text { física }\end{array}$ & $\begin{array}{l}\text { Exigência de posturas } \\
\text { inadequadas e } \\
\text { movimentação de cargas } \\
\text { individualmente. }\end{array}$ \\
\hline 4 & $\begin{array}{l}\text { LANDI, R. S. Avaliação } \\
\text { de fatores ergonômicos } \\
\text { em atividades de um } \\
\text { viveiro florestal. Jerônimo } \\
\text { Monteiro, 2012. Dissertação, } \\
\text { Universidade Federal do } \\
\text { Espírito Santo. }\end{array}$ & $\begin{array}{l}\text { Ergonomia } \\
\text { física }\end{array}$ & $\begin{array}{l}\text { Exigências de posturas } \\
\text { inadequadas. }\end{array}$ \\
\hline 5 & $\begin{array}{l}\text { MAIA, L. R.; RODRIGUES, L. } \\
\text { B. Saúde e segurança no } \\
\text { ambiente rural: uma análise } \\
\text { das condições de trabalho } \\
\text { em um setor de ordenha. } \\
\text { Ciência Rural, jun. 2012. v. 42, } \\
\text { n. } 6, \text { p. 1134-1139. }\end{array}$ & $\begin{array}{l}\text { Ergonomia } \\
\text { física }\end{array}$ & $\begin{array}{l}\text { Exigência de posturas } \\
\text { inadequadas e } \\
\text { movimentos repetitivos. }\end{array}$ \\
\hline
\end{tabular}

\begin{tabular}{|c|c|c|c|}
\hline 6 & $\begin{array}{l}\text { RENNÓ, C. O. Análise postural } \\
\text { da equipe de enfermagem } \\
\text { durante o banho no recém- } \\
\text { nascido. Rio de Janeiro, } 2012 . \\
\text { Dissertação, Universidade } \\
\text { Federal do Estado do Rio de } \\
\text { Janeiro. }\end{array}$ & $\begin{array}{l}\text { Ergonomia } \\
\text { física }\end{array}$ & $\begin{array}{l}\text { Dimensionamento } \\
\text { inadequado do posto de } \\
\text { trabalho. } \\
\text { Exigências de postura } \\
\text { inadequada. }\end{array}$ \\
\hline 7 & $\begin{array}{l}\text { SOUZA, M. G. Visão dos } \\
\text { trabalhadores acerca das } \\
\text { suas condições de trabalho } \\
\text { em um centro integrado de } \\
\text { saúde. Rio de Janeiro, } 2012 . \\
\text { Dissertação, Universidade do } \\
\text { Estado do Rio de Janeiro. }\end{array}$ & $\begin{array}{l}\text { Ergonomia } \\
\text { física e } \\
\text { organizacional }\end{array}$ & $\begin{array}{l}\text { Espaço insuficiente para } \\
\text { pessoas e equipamentos, } \\
\text { pouca ou nenhuma } \\
\text { participação do } \\
\text { trabalhador. }\end{array}$ \\
\hline 8 & $\begin{array}{l}\text { MACIEL, D. P. et al. } \\
\text { Musculoeskeletal disorder } \\
\text { related to the work of doctors } \\
\text { who perform medical } \\
\text { invasive evaluation. Work, } \\
\text { 2012. v. 41, p. 1860-1863. }\end{array}$ & $\begin{array}{l}\text { Ergonomia } \\
\text { física }\end{array}$ & $\begin{array}{l}\text { Ritmo de trabalho intenso, } \\
\text { exigências de uso da força } \\
\text { e movimentos repetitivos } \\
\text { das mãos, insuficiência de } \\
\text { pausas. }\end{array}$ \\
\hline 9 & $\begin{array}{l}\text { MENDES, D. P. et al. Do } \\
\text { prescrito ao real: a gestão } \\
\text { individual e coletiva } \\
\text { dos trabalhadores de } \\
\text { enfermagem frente ao risco } \\
\text { de acidente de trabalho. } \\
\text { Gestão \& Produção, dez. } 2012 \text {. } \\
\text { v. 19, n. 4, p. 885-892. }\end{array}$ & $\begin{array}{l}\text { Ergonomia } \\
\text { física e } \\
\text { organizacional }\end{array}$ & $\begin{array}{l}\text { Ritmo de trabalho intenso, } \\
\text { ausência de pausas devido } \\
\text { ao } \\
\text { subdimensionamento } \\
\text { da equipe, sobrecarga } \\
\text { física, deficiências na } \\
\text { organização do trabalho. }\end{array}$ \\
\hline 10 & $\begin{array}{l}\text { BRAGA, G. W. Estudo da } \\
\text { vibração de corpo inteiro em } \\
\text { pilotos de helicoptera esquilo } \\
\text { AS-350 L1. Guaratinguetá, } \\
\text { 2012. Dissertação, } \\
\text { Universidade Estadual } \\
\text { Paulista (UNESP). }\end{array}$ & $\begin{array}{l}\text { Ergonomia } \\
\text { física }\end{array}$ & $\begin{array}{l}\text { Inadequação do mobiliário, } \\
\text { exigência de atenção. }\end{array}$ \\
\hline 11 & $\begin{array}{l}\text { SA, E. C.; FERREIRA JUNIOR, } \\
\text { M.; ROCHA, L. E. Risk } \\
\text { factors for computer visual } \\
\text { syndrome (CVS) among } \\
\text { operators of two call centers } \\
\text { in São Paulo, Brazil. Work, } \\
\text { 2012. v. 41, p. 3568-3574. }\end{array}$ & $\begin{array}{l}\text { Ergonomia } \\
\text { organizacional }\end{array}$ & $\begin{array}{l}\text { Falta de reconhecimento } \\
\text { no trabalho, deficiências } \\
\text { na organização do } \\
\text { trabalho, } \\
\text { alta demanda de trabalho. }\end{array}$ \\
\hline
\end{tabular}




\begin{tabular}{|c|c|c|c|}
\hline 12 & $\begin{array}{l}\text { HARARI, D. Fatores que } \\
\text { influenciam a prevalência de } \\
\text { queixas osteomusculares em } \\
\text { trabalhadores de diferentes } \\
\text { setores de uma indústria. } \\
\text { São Paulo, 2012. Dissertação, } \\
\text { Universidade de São Paulo. }\end{array}$ & $\begin{array}{l}\text { Ergonomia } \\
\text { física }\end{array}$ & $\begin{array}{l}\text { Ritmo de trabalho intenso, } \\
\text { ausência de segurança na } \\
\text { realização do trabalho. }\end{array}$ \\
\hline 13 & $\begin{array}{l}\text { ROCHA, L. F.; SIMONELLI, } \\
\text { A. P. A utilização da análise } \\
\text { ergonômica do trabalho } \\
\text { como ferramenta do } \\
\text { terapeuta ocupacional no } \\
\text { estudo da atividade de } \\
\text { trabalho de cabeleireiros. } \\
\text { Cadernos de Terapia } \\
\text { Ocupacional UfsCar, 2012. v. } \\
\text { 20, n. 3, p. 413-424. }\end{array}$ & $\begin{array}{l}\text { Ergonomia } \\
\text { física }\end{array}$ & $\begin{array}{l}\text { Ritmo de trabalho intenso, } \\
\text { exigências de postura } \\
\text { inadequada, insuficiência } \\
\text { de pausas. }\end{array}$ \\
\hline 14 & $\begin{array}{l}\text { CARNEIRO, T. M. Condições } \\
\text { de trabalho em enfermagem } \\
\text { na unidade de terapia } \\
\text { intensiva. Salvador, } 2013 . \\
\text { Dissertação, Universidade } \\
\text { Federal da Bahia. }\end{array}$ & $\begin{array}{l}\text { Ergonomia } \\
\text { organizacional }\end{array}$ & $\begin{array}{l}\text { Ausência de pausas devido } \\
\text { subdimensionamento da } \\
\text { equipe }\end{array}$ \\
\hline 15 & $\begin{array}{l}\text { ALEXANDRE, M. A. } \\
\text { B. Condições de } \\
\text { trabalho e desordens } \\
\text { musculoesqueléticas } \\
\text { relacionadas à coluna } \\
\text { vertebral em dentistas. Porto } \\
\text { Alegre, 2013. Dissertação, } \\
\text { Universidade Federal do Rio } \\
\text { Grande do Sul - UFRGS. }\end{array}$ & $\begin{array}{l}\text { Ergonomia } \\
\text { física }\end{array}$ & $\begin{array}{l}\text { Exigência de posturas } \\
\text { inadequadas, esforço físico, } \\
\text { movimentos repetitivos } \\
\text { e sobrecarga horária de } \\
\text { trabalho. }\end{array}$ \\
\hline 16 & $\begin{array}{l}\text { ALTOÉ, A. A. M. Condições } \\
\text { ergonômicas laborais } \\
\text { para os trabalhadores de } \\
\text { enfermagem em terapia } \\
\text { intensiva: orientações } \\
\text { sobre posturas adequadas. } \\
\text { Niterói, 2013. Dissertação, } \\
\text { Universidade Federal } \\
\text { Fluminense. }\end{array}$ & $\begin{array}{l}\text { Ergonomia } \\
\text { física e } \\
\text { organizacional }\end{array}$ & $\begin{array}{l}\text { Ausência de pausas devido } \\
\text { subdimensionamento } \\
\text { da equipe, falta de } \\
\text { informações e divulgação } \\
\text { sobre posturas a adotar } \\
\text { para evitar problemas } \\
\text { físicos, Inadequações do } \\
\text { posto de trabalho. }\end{array}$ \\
\hline
\end{tabular}

\begin{tabular}{|c|c|c|c|}
\hline 17 & $\begin{array}{l}\text { SILVA, E. E. C. M. et al. } \\
\text { Ergonomic evaluation of } \\
\text { the position of urgency in } \\
\text { a mixed health in Natal/Rio } \\
\text { Grande do Norte. Revista } \\
\text { de Pesquisa: Cuidado é } \\
\text { Fundamental Online, 2013. v. } \\
\text { 5, n. 3, p. 227-234. }\end{array}$ & $\begin{array}{l}\text { Ergonomia } \\
\text { física e } \\
\text { organizacional }\end{array}$ & $\begin{array}{l}\text { Riscos biomecânicos, } \\
\text { ausência de pausas devido } \\
\text { subdimensionamento da } \\
\text { equipe, Inadequações de } \\
\text { ferramentas, inadequações } \\
\text { do posto de trabalho e das } \\
\text { condições ambientais. }\end{array}$ \\
\hline 18 & $\begin{array}{l}\text { RANDO JÚNIOR, A. M. } \\
\text { Interferência das condições } \\
\text { ergonômicas na execução } \\
\text { de paredes de alvenaria } \\
\text { de blocos cerâmicos. } \\
\text { Londrina, 2013. Dissertação, } \\
\text { Universidade Estadual de } \\
\text { Londrina. }\end{array}$ & $\begin{array}{l}\text { Ergonomia } \\
\text { física }\end{array}$ & $\begin{array}{l}\text { Redução do risco } \\
\text { ergonômico e do tempo } \\
\text { de produção após } \\
\text { implantação de melhorias. }\end{array}$ \\
\hline 19 & $\begin{array}{l}\text { GUIMARÃES, B. M; AZEVEDO, } \\
\text { L. S. Riscos de distúrbios } \\
\text { osteomusculares em punhos } \\
\text { de trabalhadores de uma } \\
\text { indústria de pescados. } \\
\text { Fisioterapia em Movimento, } \\
\text { set. } 2013 . \text { v. 26, n. 3, p. 488- } \\
489 .\end{array}$ & $\begin{array}{l}\text { Ergonomia } \\
\text { física }\end{array}$ & $\begin{array}{l}\text { Exigência de movimentos } \\
\text { de punho. }\end{array}$ \\
\hline 20 & $\begin{array}{l}\text { BARBIERI, D. F. } \\
\text { Estudo de sintomas } \\
\text { musculoesqueléticos, fatores } \\
\text { de risco e exposição física em } \\
\text { trabalhadores de escritório. } \\
\text { São Carlos, 2013. Dissertação, } \\
\text { Universidade Federal de São } \\
\text { Carlos. }\end{array}$ & $\begin{array}{l}\text { Ergonomia } \\
\text { física, } \\
\text { organizacional } \\
\text { e cognitiva }\end{array}$ & $\begin{array}{l}\text { Exigências de posturas } \\
\text { inadequadas, necessidade } \\
\text { de ajustes organizacionais. }\end{array}$ \\
\hline 21 & $\begin{array}{l}\text { CÂNDIDO, P. E. F. Trabalho } \\
\text { e saúde mental em policiais } \\
\text { militares de Palhoça } \\
\text { (SC). Florianópolis, } 2013 . \\
\text { Dissertação, Universidade } \\
\text { Federal Santa Catarina - } \\
\text { UFSC. }\end{array}$ & $\begin{array}{l}\text { Ergonomia } \\
\text { física, } \\
\text { organizacional } \\
\text { e cognitiva }\end{array}$ & $\begin{array}{l}\text { Ausência de pausas devido } \\
\text { subdimensionamento da } \\
\text { equipe, sobrecarga mental, } \\
\text { deficiências no processo } \\
\text { de trabalho. }\end{array}$ \\
\hline
\end{tabular}




\begin{tabular}{|c|c|c|c|}
\hline 22 & $\begin{array}{l}\text { ARAÚJO, F. M. Avaliação das } \\
\text { condições de trabalho do } \\
\text { cirurgião em procedimentos } \\
\text { eletivos em dois hospitais } \\
\text { públicos em São Luís - MA. } \\
\text { São Luís, 2014. Dissertação, } \\
\text { Universidade Federal do } \\
\text { Maranhão. }\end{array}$ & $\begin{array}{l}\text { Ergonomia } \\
\text { física }\end{array}$ & $\begin{array}{l}\text { Inadequações do } \\
\text { mobiliário e ambiente, } \\
\text { inconformidades de } \\
\text { equipamentos, equipe } \\
\text { subdimensionada. }\end{array}$ \\
\hline 23 & $\begin{array}{l}\text { ABDALLA, D. R. et al. Postural } \\
\text { biomechanical risks for } \\
\text { nursing workers. Fisioterapia } \\
\text { em Movimento, set. 2014. v. } \\
27, \text { n. 3, p. 421-427. }\end{array}$ & $\begin{array}{l}\text { Ergonomia } \\
\text { física }\end{array}$ & $\begin{array}{l}\text { Jornada de trabalho } \\
\text { superior à normalidade, } \\
\text { posturas inadequadas. }\end{array}$ \\
\hline 24 & $\begin{array}{l}\text { ZANOL, E. J. Avaliação } \\
\text { dos níveis de vibração } \\
\text { de corpo inteiro sofridos } \\
\text { por motoristas de ônibus } \\
\text { urbanos em diferentes tipos } \\
\text { de pistas. Porto Alegre, } \\
\text { 2014. Dissertação, Escola de } \\
\text { Engenharia da Universidade } \\
\text { Federal do Rio Grande do Sul. }\end{array}$ & $\begin{array}{l}\text { Ergonomia } \\
\text { física }\end{array}$ & $\begin{array}{l}\text { Ineficiência da poltrona } \\
\text { quanto à absorção da } \\
\text { vibração. }\end{array}$ \\
\hline 25 & $\begin{array}{l}\text { TEIXEIRA, C. L. Estudo } \\
\text { ergonômico do trabalho dos } \\
\text { músicos de uma orquestra } \\
\text { sinfônica. Campinas, } 2014 . \\
\text { Dissertação, Universidade } \\
\text { Estadual de Campinas - } \\
\text { UNICAMP. }\end{array}$ & $\begin{array}{l}\text { Ergonomia } \\
\text { física }\end{array}$ & $\begin{array}{l}\text { Posturas inadequadas, } \\
\text { movimentos repetitivos. }\end{array}$ \\
\hline 26 & $\begin{array}{l}\text { SILVA, J. R. M.; TEIXEIRA, R. } \\
\text { L. Sobrecarga térmica em } \\
\text { fábrica de móveis. Floresta e } \\
\text { Ambiente, dez. 2014. v. 21, n. } \\
\text { 4, p. 494-500. }\end{array}$ & $\begin{array}{l}\text { Ergonomia } \\
\text { física }\end{array}$ & $\begin{array}{l}\text { Inadequação do ambiente } \\
\text { em relação ao conforto } \\
\text { térmico. }\end{array}$ \\
\hline 27 & $\begin{array}{l}\text { CARMO, M. M. Tribunal da } \\
\text { cidadania?! Pra quem?!" : } \\
\text { Qualidade de vida no } \\
\text { trabalho em um órgão do } \\
\text { poder judiciário brasileiro. } \\
\text { Brasília, 2014. Dissertação, } \\
\text { Universidade de Brasília. }\end{array}$ & $\begin{array}{l}\text { Ergonomia } \\
\text { organizacional } \\
\text { e cognitiva }\end{array}$ & $\begin{array}{l}\text { Pouca ou nenhuma } \\
\text { participação do } \\
\text { trabalhador, ritmo de } \\
\text { trabalho intenso, ausência } \\
\text { de pausas, deficiências na } \\
\text { organização do trabalho. }\end{array}$ \\
\hline
\end{tabular}

\begin{tabular}{|c|c|c|c|}
\hline 28 & $\begin{array}{l}\text { SHIMANO, S. G. N.; WALSH, } \\
\text { I. A. P.; FONSECA, M. C. R. } \\
\text { Assessment of the perception } \\
\text { of aerobatic pilots regarding } \\
\text { flight activity. Fisioterapia em } \\
\text { Movimento, mar. 2015. v. } 28, n \text {. } \\
\text { 1, p. 141-148. }\end{array}$ & $\begin{array}{l}\text { Ergonomia } \\
\text { física }\end{array}$ & $\begin{array}{l}\text { Condições ambientais } \\
\text { desconfortáveis (calor). } \\
\text { Uso de força física. }\end{array}$ \\
\hline 29 & $\begin{array}{l}\text { AZEVEDO, E. R. F. Análise } \\
\text { do trabalho e da saúde das } \\
\text { mulheres que desempenham } \\
\text { a função de limpeza no } \\
\text { polo universitário de Volta } \\
\text { Redonda. Niterói, 2015. } \\
\text { Dissertação, Universidade } \\
\text { Federal Fluminense. }\end{array}$ & $\begin{array}{l}\text { Ergonomia } \\
\text { física }\end{array}$ & $\begin{array}{l}\text { Trabalho precário e } \\
\text { desvalorizado pela } \\
\text { sociedade. }\end{array}$ \\
\hline 30 & $\begin{array}{l}\text { MARQUES, G. M.; SILVA- } \\
\text { JUNIOR, J. S. Síndrome } \\
\text { do manguito rotador em } \\
\text { trabalhadores de linha de } \\
\text { montagem de caminhões. } \\
\text { Cadernos Saúde Coletiva, set. } \\
\text { 2015. v. 23, n. 3, p. 323-329. }\end{array}$ & $\begin{array}{l}\text { Ergonomia } \\
\text { física }\end{array}$ & $\begin{array}{l}\text { Inadequação do posto de } \\
\text { trabalho. }\end{array}$ \\
\hline 31 & $\begin{array}{l}\text { VASCONCELOS, F. M. et } \\
\text { al. Riscos no ambiente } \\
\text { de trabalho no setor de } \\
\text { panificação: um estudo de } \\
\text { caso em duas indústrias de } \\
\text { biscoitos. Gestão \& Produção, } \\
\text { set. } 2015 \text {. v. 22, n. 3, p. 565-589. }\end{array}$ & $\begin{array}{l}\text { Ergonomia } \\
\text { física }\end{array}$ & $\begin{array}{l}\text { Posturas inadequadas, } \\
\text { movimentos repetitivos. }\end{array}$ \\
\hline 32 & $\begin{array}{l}\text { OLIVEIRA, J. A. N. Avaliação } \\
\text { de riscos ergonômicos nos } \\
\text { profissionais de enfermagem } \\
\text { do serviço de atendimento } \\
\text { móvel de urgência - } \\
\text { SAMU/Recife. Recife, } 2015 . \\
\text { Dissertação, Universidade } \\
\text { Federal de Pernambuco. }\end{array}$ & $\begin{array}{l}\text { Ergonomia } \\
\text { física }\end{array}$ & $\begin{array}{l}\text { Exigência de posturas } \\
\text { inadequadas, esforço físico. }\end{array}$ \\
\hline
\end{tabular}




\begin{tabular}{|c|c|c|c|}
\hline 33 & $\begin{array}{l}\text { OLIVEIRA, R. L. M. O } \\
\text { desempenho da ergonomia } \\
\text { na análise de custos } \\
\text { humanos em atividades } \\
\text { de alto risco: o caso do } \\
\text { hidrojatista em linhas de } \\
\text { pintura na industria pesada. } \\
\text { Recife, 2015. Dissertação, } \\
\text { Universidade Federal de } \\
\text { Pernambuco - UFPE. }\end{array}$ & $\begin{array}{l}\text { Ergonomia } \\
\text { física }\end{array}$ & $\begin{array}{l}\text { Excesso de ruído e } \\
\text { sobrecarga térmica, } \\
\text { deficiência de iluminação, } \\
\text { problemas no manejo dos } \\
\text { equipamentos. }\end{array}$ \\
\hline 34 & $\begin{array}{l}\text { BRITO, K. M. F. Riscos à } \\
\text { saúde dos trabalhadores } \\
\text { em unidade de alimentação } \\
\text { e nutrição de um Hospital } \\
\text { Universitário. Natal, } 2015 . \\
\text { Dissertação, Universidade } \\
\text { Federal do Rio Grande do } \\
\text { Norte. }\end{array}$ & $\begin{array}{l}\text { Ergonomia } \\
\text { física e } \\
\text { organizacional }\end{array}$ & $\begin{array}{l}\text { Pouca ou nenhuma } \\
\text { participação do } \\
\text { trabalhador, inadequação } \\
\text { de mobiliário, posturas } \\
\text { inadequadas, ausência } \\
\text { de pausas, problemas de } \\
\text { organização do trabalho. }\end{array}$ \\
\hline 35 & $\begin{array}{l}\text { SALA, S. M. F. Ergonomia } \\
\text { aplicada a ferramentas } \\
\text { manuais: o caso da } \\
\text { ferramenta manual para } \\
\text { descascamento de raízes de } \\
\text { mandiocas. Florianópolis, } \\
\text { 2015. Dissertação, } \\
\text { Universidade Federal de } \\
\text { Santa Catarina - UFSC. }\end{array}$ & $\begin{array}{l}\text { Ergonomia } \\
\text { física }\end{array}$ & $\begin{array}{l}\text { Inadequação } \\
\text { antropométrica de } \\
\text { ferramentas. }\end{array}$ \\
\hline 36 & $\begin{array}{l}\text { NOVAES, A. L. T. Colheita de } \\
\text { mexilhões cultivados em } \\
\text { Santa Catarina: desempenho } \\
\text { operacional, ergonomia e } \\
\text { prototipagem de um sistema } \\
\text { mecanizado.Florianópolis, } \\
\text { 2015. Tese, Universidade } \\
\text { Federal de Santa Catarina - } \\
\text { UFSC. }\end{array}$ & $\begin{array}{l}\text { Ergonomia } \\
\text { física }\end{array}$ & $\begin{array}{l}\text { Exigência de postura } \\
\text { inadequada. }\end{array}$ \\
\hline 37 & $\begin{array}{l}\text { BARBOSA, V. A. Avaliação } \\
\text { ergonômica da colheita } \\
\text { florestal em área com } \\
\text { madeira danificada } \\
\text { pelo vento. Jerônimo } \\
\text { Monteiro, 2015. Dissertação, } \\
\text { Universidade Federal do } \\
\text { Espírito Santo. }\end{array}$ & $\begin{array}{l}\text { Ergonomia } \\
\text { física e } \\
\text { organizacional }\end{array}$ & $\begin{array}{l}\text { Pouca ou nenhuma } \\
\text { participação do } \\
\text { trabalhador, exigência de } \\
\text { posturas inadequadas, } \\
\text { uso de forças, exposição } \\
\text { a vibrações e ruídos, } \\
\text { insuficiência de } \\
\text { informações para o } \\
\text { trabalhador. }\end{array}$ \\
\hline
\end{tabular}

\begin{tabular}{|c|c|c|c|}
\hline 38 & $\begin{array}{l}\text { VILELA, R. A. G. et al. Pressão } \\
\text { por produção e produção de } \\
\text { riscos: a "maratona" perigosa } \\
\text { do corte manual da cana-de- } \\
\text { açúcar. Revista Brasileira de } \\
\text { Saúde Ocupacional, jun. } 2015 . \\
\text { v. } 40, \text { n. } 131 \text {, p. 30-48 }\end{array}$ & $\begin{array}{l}\text { Ergonomia } \\
\text { física e } \\
\text { organizacional }\end{array}$ & $\begin{array}{l}\text { Ritmo de trabalho intenso } \\
\text { (pagamento por produção). }\end{array}$ \\
\hline 39 & $\begin{array}{l}\text { ESTEVAM, F. N. L. Variáveis } \\
\text { ambientais e ergonômicas na } \\
\text { operação com microtrator. } \\
\text { Fortaleza, 2015. Dissertação, } \\
\text { Universidade Federal do } \\
\text { Ceará. }\end{array}$ & $\begin{array}{l}\text { Ergonomia } \\
\text { física }\end{array}$ & $\begin{array}{l}\text { Alta carga térmica, } \\
\text { inadequação do } \\
\text { equipamento. }\end{array}$ \\
\hline 40 & $\begin{array}{l}\text { MEDEIROS, L. G. R. Análise } \\
\text { da atividade das psicólogas } \\
\text { de CRAS do vale do Sabugi- } \\
\text { PB. João Pessoa, } 2015 . \\
\text { Dissertação, Universidade } \\
\text { Federal da Paraíba - UFPB. }\end{array}$ & $\begin{array}{l}\text { Ergonomia } \\
\text { física, } \\
\text { organizacional } \\
\text { e cognitiva }\end{array}$ & $\begin{array}{l}\text { Formação insuficiente } \\
\text { para a função, falta de } \\
\text { reconhecimento pela } \\
\text { gestão, deficiências na } \\
\text { organização do trabalho } \\
\text { e relações entre as } \\
\text { psicólogas e os pacientes }\end{array}$ \\
\hline 41 & $\begin{array}{l}\text { BARBOSA, J. S. V. O trabalhar } \\
\text { com médicos obstetras. João } \\
\text { Pessoa, 2016. Dissertação, } \\
\text { Universidade Federal da } \\
\text { Paraíba. }\end{array}$ & $\begin{array}{l}\text { Ergonomia } \\
\text { organizacional } \\
\text { e cognitiva }\end{array}$ & $\begin{array}{l}\text { Deficiências na } \\
\text { organização do trabalho e } \\
\text { relações entre os médicos } \\
\text { e os pacientes. }\end{array}$ \\
\hline 42 & $\begin{array}{l}\text { SILVA, J. R. R. et al. Análise } \\
\text { ergonômica da tarefa dos } \\
\text { enfermeiros das clínicas } \\
\text { cirúrgicas da internação } \\
\text { do hospital das clínicas da } \\
\text { UFPE: um estudo com o } \\
\text { uso da termografia digital. } \\
\text { São Paulo: } 1 \text { Congresso } \\
\text { Internacional de Ergonomia } \\
\text { aplicada, dez. 2016. p. 686- } \\
696 .\end{array}$ & $\begin{array}{l}\text { Ergonomia } \\
\text { física }\end{array}$ & $\begin{array}{l}\text { Ritmo de trabalho intenso, } \\
\text { exigências de postura } \\
\text { inadequada. }\end{array}$ \\
\hline 43 & $\begin{array}{l}\text { MATOS, I. C. Condições } \\
\text { de trabalho e os seus } \\
\text { impactos na saúde em } \\
\text { uma unidade de produção } \\
\text { de imunobiológicos da } \\
\text { FIOCRUZ. Rio de Janeiro, } \\
\text { 2016. Dissertação, Escola } \\
\text { Nacional de Saúde Pública } \\
\text { Sérgio Arouca. }\end{array}$ & $\begin{array}{l}\text { Ergonomia } \\
\text { física e } \\
\text { organizacional }\end{array}$ & $\begin{array}{l}\text { Exigência de postura } \\
\text { inadequada, ritmo } \\
\text { de trabalho intenso, } \\
\text { dimensionamento } \\
\text { inadequado do } \\
\text { posto de trabalho, } \\
\text { subdimensionamento da } \\
\text { equipe, exigência cognitiva } \\
\text { alta. }\end{array}$ \\
\hline
\end{tabular}




\begin{tabular}{|l|l|l|l|}
\hline 44 & $\begin{array}{l}\text { SANTOS, B. D. Alternativas } \\
\text { mitigadoras de riscos } \\
\text { ocupacionais no exercício } \\
\text { profissional de catadores } \\
\text { de materiais recicláveis } \\
\text { vinculados à ARENSA, } \\
\text { Campina Grande - PB. } \\
\text { Campina Grande, 2016. } \\
\text { Dissertação, Universidade } \\
\text { Estadual da Paraíba. }\end{array}$ & $\begin{array}{l}\text { Ergonomia } \\
\text { física }\end{array}$ & $\begin{array}{l}\text { Esforço físico intenso, } \\
\text { levantamento e } \\
\text { transporte individual } \\
\text { de cargas, exigência de } \\
\text { postura inadequada, } \\
\text { uso prolongado de voz, } \\
\text { conflitos. }\end{array}$ \\
\hline 45 & $\begin{array}{l}\text { SOUZA, J. A. C.; MAZINI } \\
\text { FILHO, M. L. Análise } \\
\text { ergonômica dos movimentos } \\
\text { e posturas dos operadores } \\
\text { de checkout em um } \\
\text { supermercado localizado na } \\
\text { cidade de Cataguases, Minas } \\
\text { Gerais. Gestão \& Produção, } \\
\text { abr. 2017. v. 24, n. 1, p. 123-135. }\end{array}$ & $\begin{array}{l}\text { Ergonomia } \\
\text { física }\end{array}$ & $\begin{array}{l}\text { Posturas inadequadas, } \\
\text { sobrecarga física, } \\
\text { movimentos repetitivos, } \\
\text { posto de trabalho } \\
\text { inadequado. }\end{array}$ \\
\hline 46 & $\begin{array}{l}\text { GIRARDI, B. B. et al. Relação } \\
\text { entre condições de trabalho } \\
\text { e sintomas vocais em } \\
\text { operadores de um call } \\
\text { center modelo. Audiology - } \\
\text { Communication Research, } \\
\text { 2017. v. 22, e-1738. }\end{array}$ & $\begin{array}{l}\text { Ergonomia } \\
\text { organizacional }\end{array}$ & $\begin{array}{l}\text { Uso prolongado da voz, } \\
\text { ausência de programas de } \\
\text { saúde vocal. }\end{array}$ \\
\hline
\end{tabular}

Fonte: elaborado pelos autores

Conforme exposto no quadro 1, diversos estudos objetivam pesquisar aspectos ligados às exigências físicas (41) do trabalho, porém nos resultados são identificados aspectos ligados à organização do trabalho que contribuem significativamente para tais exigências impostas ao trabalhador. Assim, é possível destacar que a relação entre os domínios da ergonomia devem estar em equilíbrio para evitar doenças ao trabalhador.

Dessa forma, os principais resultados também se concentraram naqueles ligados às exigências físicas, sendo posturas inadequadas, movimentos repetitivos, movimentação individual de cargas com excesso de peso, dimensionamento inadequado do posto de trabalho, uso de força, inadequações de ferramentas ou das condições ambientais. Por outro lado, demandas ligadas à organização do trabalho foram a ausência ou insuficiência de pausas, deficiências no processo de trabalho, pouca ou nenhuma participação do trabalhador, exigência de ritmo intenso de trabalho, falta de reconhecimento no trabalho, subdimensionamento de equipes de trabalho, falta de treinamentos e sobrecarga da jornada de trabalho. Quanto às exigências cognitivas, os estudos foram mais tímidos e os resultados apontaram exigência de atenção e sobrecarga mental. Assim, a carga cognitiva ainda merece mais destaque e novos estudos devem ser propostos devido sua importância para a saúde do trabalhador.

Dentre as pesquisas, a maior parte selecionou como população os trabalhadores da área da saúde, como enfermeiros, médicos e psicólogas, ou ainda que trabalham em hospitais (ABDALLA et al., 2014; ALEXANDRE, 2013; ALTOÉ, 2013; ARAÚJO, 2014; BARBOSA, 2016; BRITO, 2015; CARNEIRO, 2013; MACIEL et al., 2012; MATOS, 2016; MEDEIROS, 2015; MENDES et al., 2012; OLIVEIRA, 2015b; RENNÓ, 2012; SILVA et al., 2016, 2013; SOUZA, 2012). Além destes, também foram realizado estudos incluindo trabalhadores rurais (BARBOSA, 2015; BRITTO, 2012; CARVALHO et al., 2012; ESTEVAM, 2015; LANDI, 2012; MAIA; RODRIGUES, 2012; NOVAES, 2015; SALA, 2015; VILELA et al., 2015), trabalhadores industriais (GUIMARÃES; AZEVEDO, 2013; HARARI, 2012; MARQUES; SILVA-JUNIOR, 2015; OLIVEIRA, 2015a; SILVA; TEIXEIRA, 2014; VASCONCELOS et al., 2015), trabalhadores ligados à limpeza (AZEVEDO, 2015; ESTEVO, 2012; SANTOS, 2016), pilotos de aeronave (BRAGA, 2012; SHIMANO; WALSH; FONSECA, 2015), operadores de call center (GIRARDI et al., 2017; SA; FERREIRA JUNIOR; ROCHA, 2012), operadores de checkout (SOUZA; MAZINI FILHO, 2017), cabeleireiros (ROCHA; SIMONELLI, 2012), trabalhadores da construção civil (RANDO JÚNIOR, 2013), trabalhadores de escritório (BARBIERI, 2013), policiais militares (CÂNDIDO, 2013), motoristas de ônibus (ZANOL, 2014), músicos (TEIXEIRA, 2014), trabalhadores do setor público judiciário (CARMO, 2014). Assim, observa-se a diversidade na seleção da população, com maior ênfase para os trabalhadores da área da saúde (tabela 1).

\begin{tabular}{|c|c|c|c|c|c|c|c|c|}
\hline $\begin{array}{l}\text { População/ } \\
\text { Ano }\end{array}$ & Saúde & Rural & Industrial & $\begin{array}{c}\text { Setor } \\
\text { limpeza }\end{array}$ & $\begin{array}{l}\text { Piloto de } \\
\text { aeronave }\end{array}$ & $\begin{array}{l}\text { Operador de } \\
\text { call center }\end{array}$ & Outros & Total/ ano \\
\hline 2012 & 4 & 4 & 1 & 1 & 1 & 1 & 4 & 16 \\
\hline 2013 & 4 & & 1 & & & & 3 & 8 \\
\hline 2014 & 2 & & 1 & & & & & 3 \\
\hline 2015 & 3 & 5 & 3 & 1 & 1 & & & 13 \\
\hline 2016 & 3 & & & 1 & & 1 & 1 & 6 \\
\hline Estudos/área & 16 & 9 & 6 & 3 & 2 & 2 & 8 & \\
\hline
\end{tabular}

Da mesma forma, a concentração dos estudos reside em dissertações, totalizando 29 trabalhos, restando 17 artigos e uma tese. Tais números representam a carência de publicações e pesquisas ampliadas na área. Além disso, há descontinuidade na publicação de trabalhos, exceção apenas para a área da saúde. Os anos de 2012 e 2015 foram aqueles que mais apresentaram publicações (tabela 1).

\section{Discussão}

O texto da NR-17 e seus anexos possuem potencialidades que devem ser destacadas, como a existência da norma e a indicação de uma metodologia para a análise (AET). Porém, pontos frágeis que precisam ser reavaliados incluem a não obrigatoriedade da AET e a inexistência da indicação do profissional apto a elaborá-la.

O "Manual de aplicação da norma regulamentadora 17" (Manual de Aplicação da Norma Regulamentadora 17, 2002) criado por auditores fiscais para apoiar profissionais na implantação da NR-17 tenta sanar dúvidas relacionadas à norma. Porém, o anexo 
de teleatendimento/ telemarketing (anexo 2) apresenta texto mais específico, atualizado e de maior compreensão, mesmo porque levou em consideração as queixas dos trabalhadores, inconformidades encontradas em fiscalizações e resultados de pesquisas científicas para sua formulação (PERES et al., 2006).

\section{Esforço e postura}

Em relação ao levantamento, transporte e descarga individual de materiais (item 17.2), a norma descreve que o peso da carga não deverá ultrapassar o limite de esforço compatível com o trabalhador e que um treinamento deverá ser realizado se a carga for considerada pesada. Além disso, destaca que a mulher ou o jovem devem carregar peso menor do que os homens. Neste momento, o entendimento da norma fica comprometido pela ausência de um parâmetro numérico e especifico, ou outra referência que determine a carga em questão.

Ainda quanto ao peso da carga, a CLT no artigo 198 indica $60 \mathrm{~kg}$ como peso máximo e o MTE pode fixar valores para a movimentação individual das cargas, mas ainda não o fez.

Segundo pesquisa feita pelo National Institute for Occupational Safety and Health (NIOSH), com base em um peso constante de $23 \mathrm{~kg}$ é possível calcular o peso de carga especifico para cada trabalhador (WATERS; PUTZ-ANDERSON; GARG, 1994). Seria aconselhável citar essa referência na NR-17, a exemplo da NR-9 - PPRA que indica que na ausência de valores nacionais para contaminantes do ambiente de trabalho é possível utilizar os dados da American Conference of Governmental Industrial Hygienists (ACGIH). Certamente, um parâmetro claro facilitaria a descrição das tarefas e os controles necessários pela organização da empresa e pela fiscalização.

Outro indicador de intensidade de esforço que poderia ser adotado é a frequência cardíaca, que se ajusta proporcionalmente em relação ao esforço físico (VILELA et al., 2015). Além disso, a carga cardiovascular é o índice mais usado para avaliar o impacto fisiológico do trabalho pois corresponde à percentagem da frequência cardíaca em relação à frequência cardíaca máxima admitida, sendo $40 \%$ para atividades média e leve, ou 33\% para atividades intensas (BARBOSA, 2015; VILELA et al., 2015). Desse modo, é possível definir o peso a ser transportado individualmente pelo trabalhador, informação que seria útil se indicada na NR-17.

A análise biomecânica realizada com trabalhadores de galpões de frango durante o abastecimento do carrinho com lenha para as campânulas e de ração para os comedouros identificou que estavam expostos aos riscos de lesões articulares por não haver uma carga determinada como referência (CARVALHO et al., 2012). A mesma situação foi encontrada em trabalhadores com dores nos ombros e pernas na colheita florestal, justificada pelo peso transportado manualmente em locais de difícil acesso (BRITTO, 2012).

Vasconcelos e colaboradores (2015) avaliaram a atividade de moldar biscoitos na pingadeira e Altoé (2013) avaliou uma equipe de enfermagem de terapia intensiva, ambos detectaram riscos ergonômicos que comprometiam a saúde e o sistema muscular, situação propícia a causar lesões por esforços repetitivos (LER) e distúrbios osteomusculares relacionados ao trabalho (DORT). Da mesma forma, em pesquisa realizada em posto de urgência de saúde os resultadosforam semelhantese constataram ainda que $o$ ambiente diferente do ideal pode contribuir para o aparecimento de problemas físicos, psíquicos e incapacitar o trabalhador (SILVA et al., 2013).
As exigências posturais também foram estudadas em músicos de orquestra sinfônica e a longa permanência em posições específicas e inadequadas foi confirmada. Tal fato leva os músicos ao adoecimento e abandono da profissão. Nesse caso, o desafio ergonômico está em não poder intervir diretamente nos instrumentos musicais, que oferecem riscos biomecânicos principalmente LER e DORT (TEIXEIRA, 2014).

Nos estudos com a produção de mexilhões (NOVAES, 2015) e na indústria de pescados (GUIMARÃES; AZEVEDO, 2013), que utilizam a mão-de-obra de forma intensa, os pesquisadores identificaram posturas nocivas à saúde e movimentos específicos de punho. Igualmente em atividades realizadas em viveiro florestal (LANDI, 2012) e nas ocupações do setor de limpeza (AZEVEDO, 2015) foram consideradas atividades de alto risco para o desenvolvimento dos DORT além de salários baixos e no caso da limpeza, desvalorização pela sociedade.

Outros estudos na área da saúde, com equipes de enfermagens do sistema de atendimento móvel de urgência (OLIVEIRA, 2015b), do atendimento de cuidados com os recém-nascidos (RENNÓ, 2012) e em hospital (ABDALLA et al., 2014) indicaram posturas inadequadas, esforço nas tarefas reais evidenciados pelos processos inflamatórios, fadiga e organização do posto de trabalho incompatível aos aspectos ergonômicos.

Nas estações de checkout, os movimentos executados durante as atividades em terminais de vídeo e dispositivos móveis favorecem o surgimento de DORT. Conforme estudo realizado em supermercado, a função de caixa expõe os trabalhadores principalmente à LER/DORT e à posturas inadequadas (SOUZA; MAZINI FILHO, 2017).

De maneira geral, além dos segmentos ocupacionais já citados, o cultivo da mandioca (SALA, 2015), o setor de ordenha (MAIA; RODRIGUES, 2012), em pilotos (SHIMANO; WALSH; FONSECA, 2015), indústria de montagem de caminhões (MARQUES; SILVA-JUNIOR, 2015), ambientes com pouca ou nenhuma conformidade ergonômica (BRITO, 2015) interferem diretamente na vida do trabalhador, com os DORT totalizando $30 \%$ das doenças ocupacionais no mundo (HARARI, 2012). Assim, é possível perceber a presença dos riscos ergonômicos em diversos tipos de trabalho.

Da mesma forma, a análise dos estudos realizados que apontam elevada exigência física refletem problemas de organização do trabalho, mostrando o quão as três dimensões da ergonomia - física, cognitiva e organizacional - estão interligadas e a importância de encontrar um equilíbrio entre elas.

\section{Condições ambientais}

Os pesquisadores Silva e Teixeira (2014) realizaram avaliações de sobrecarga térmica em uma fábrica de móveis e apontaram que as condições de salubridade conforme NR-15, que trata sobre condições insalubres, foram atendidas mas as condições de conforto solicitadas pela NR-17 (item 17.5.2) não estavam adequadas. As condições listadas na NR-15 tratam de situações extremas de trabalho e passíveis de percepção de adicional de insalubridade, já aquelas listadas na NR-17 citam as condições de conforto do ambiente de trabalho, ou seja, quando há exigência intelectual e atenção.

Para Montmollin e Darses (1990) as regras adotadas para as condições de conforto são de grande valia, observando-se a atividade e o local de trabalho. Os parâmetros referenciados se tornam úteis quando o ambiente onde o trabalho é executado for leve. Para situações diferentes, é importante verificar a adequação do ambiente, por exemplo, o calor excessivo onde a temperatura e umidade não favorecem a troca térmica corpo-ambiente, a ventilação poderia ser uma alternativa (MORAES, 2007). 
Igualmente, Oliveira (2015a) identificou problemas de ruído, iluminação, vibrações, ambiente térmico e qualidade do ar em uma indústria de linhas de pintura a jato que agrediam diariamente a saúde do trabalhador. Os dados encontrados ultrapassaram inclusive as condições citadas na NR-15, que possui faixa de valores ampliada quando comparada à NR-17. Então, mesmo com a obrigação da observância da NR-15 muitas empresas ainda não cumprem integralmente os preceitos da legislação, permanecendo com condições e ambientes de trabalho inadequados.

Dois estudos realizados, com pilotos de helicópteros (BRAGA, 2012) e com motoristas de ônibus (ZANOL, 2014), revelaram que os assentos das poltronas não estavam apropriados para a absorção da vibração, sendo causa de doenças para esses trabalhadores, principalmente lombalgias. Em ambas situações, se a NR-17 tivesse sido observada, o transtorno poderia ser evitado. Tal fator aponta que, além da clareza dos itens da NR-17, é importante cumpri-la para melhorar as situações de trabalho.

Assim, os postos de trabalho deveriam ser ajustados em sua totalidade com base nos domínios da ergonomia favorecendo a adequação nas interfaces humanotrabalho-ambiente, afirmando a importância da clareza da NR-17.

\section{Análise ergonômica do Trabalho (AET)}

Outro item citado na NR-17 é sobre a metodologia AET a ser adotada para identificar os riscos ergonômicos. Para a elaboração do documento é necessária a compreensão das informações descritas para que a análise seja de fato um documento que, ao ser aplicado, traga resultados positivos. Diversos estudos confirmam a importância e adequação da AET e como ela pode contribuir para melhorar os pontos críticos nas condições do trabalho (AZEVEDO, 2015; BRITO, 2015; MENDES et al., 2012; OLIVEIRA, 2015a; ROCHA; SIMONELLI, 2012; VILELA et al., 2015).

A NR-17 cita também que cabe ao empregador realizar a AET (17.1.2) mas não indica o profissional apto a realizar esta análise, deixando margem a interpretações equivocadas sob o ponto de vista legal e gerando conflitos entre os profissionais que atuam em áreas próximas à ergonomia. O profissional indicado é o ergonomista por ter conhecimento da metodologia apropriada para identificar os riscos ergonômicos e realizar a intervenção mais adequada.

As ameaças externas, ou seja, quando os trabalhadores realizam suas atividades em locais não fixos e/ou abertos, como as ruas para os policias (CÂNDIDO, 2013) e catadores de materiais recicláveis (SANTOS, 2016) ou coletores de lixo (ESTEVO, 2012), regiões da periferia da cidade para as psicólogas (MEDEIROS, 2015), o ambiente rural para os agricultores (ESTEVAM, 2015) favorecem situações complexas, o que exige um profissional capacitado para identificar tais riscos.

Outro aspecto importante é a não obrigatoriedade da realização da $A E T$, diferente de documentos citados em outras NR, como exemplo o programa de prevenção de riscos ambientais (PPRA) citado na NR-9, o programa de controle médico de saúde ocupacional (PCMSO) citado na NR-7, que são obrigatórios para empresas que tem empregados regidos pela CLT. A obrigatoriedade de elaboração da AET poderia representar um grande avanço para a segurança e saúde do trabalhador, pois estimularia as empresas a controlar os riscos ergonômicos, além de auxiliar em elementos de decisão da organização do trabalho como pausas, retorno gradativo, entre outros.

A NR-17 aborda que as situações de trabalho devem estar adequadas às características psicofisiológicas do trabalhador (Manual de Aplicação da Norma

Regulamentadora 17, 2002) e isso implica em pelo menos dois fatores: sagacidade do analista, que confirma a competência do ergonomista para realizar a $A E T$, e a participação do trabalhador na análise.

Quanto à participação, o anexo 2 da norma está mais atualizado (8.4.1) e indica a participação do trabalhador na AET pois poderá contribuir na alteração de processos, bem como na reformulação do seu ambiente de trabalho. A não participação dos trabalhadores em decisões ligadas ao seu trabalho é identificada como fragilidade de organização e processo (BRITO, 2015; CARMO, 2014; SOUZA, 2012). Ainda, acidentes e doenças ocupacionais podem ser gerados quando as informação relacionadas à ergonomia e segurança não são divulgadas para os trabalhadores, ou quando não recebem as orientações para a execução das suas atividades (BARBOSA, 2015).

\section{Organização do Trabalho}

Para a aplicação da NR-17, em relação à organização do trabalho, esta restringe as jornadas de trabalho e descreve situações de pausas que as empresas devem seguir. Um estudo identificou as pausas como mantenedoras da saúde de coletores de lixo (ESTEVO, 2012) uma vez que, com a interrupção do trabalho, conseguem alternar suas posturas, recuperando a oxigenação tecidual além de aumentar seu rendimento. Um importante avanço descrito no anexo da NR-17 foi a permissão das pausas para trabalhadores de teleatendimento/telemarketing para conversar com profissionais especializados ou colegas após sofrerem agressões verbais ou situações desgastantes.

Outro fator importante ligado à organização do trabalho é a relação interpessoal, como exemplo aquelas entre médicos e pacientes, em certas situações violentas no que diz respeito ao beneficiário e o serviço de baixa qualidade (BARBOSA, 2016). Na NR-17 o item organização do trabalho (17.6) é pouco esclarecedor e orientativo, o que mais uma vez requer um profissional apto para realizar tal análise.

Um estudo realizado em unidade de produção de imunobiológicos relacionou os distúrbios osteomusculares às exigências posturais das máquinas utilizadas e ao ritmo de trabalho intenso (MATOS, 2016). Semelhantes resultados apresentaram estudos realizados com cabeleireiros (ROCHA; SIMONELLI, 2012) e médicos (MACIEL et al., 2012), onde a ausência de pausas contribuiu para a sobrecarga de diversos segmentos musculares.

A sobrecarga de trabalho é fator apontado pelo anexo 2 (item 5.2) que pode ser evitada com a adequação do quadro de trabalhadores na empresa. Diversos estudos identificaram como principal causa de estresse ocupacional a sobrecarga de trabalhadores devido ao subdimensionamento das equipes de trabalho (ALTOÉ, 2013; ARAÚJO, 2014; BRITO, 2015; CÂNDIDO, 2013; CARMO, 2014; CARNEIRO, 2013; MENDES et al., 2012; SILVA et al., 2013) Além deste, outros problemas ligados à organização do trabalho foram as características da tarefa, avaliações dos trabalhadores, diferença entre vínculos, remuneração e carga horária entre trabalhadores com a mesma função e a falta de orientação e objetivos claros por parte da chefia (BRITO, 2015; CARMO, 2014).

Ainda no anexo 2 , os índices de monitoramento de produtividade não podem ser utilizados para o rendimento (item 5.9), sendo o ritmo de trabalho identificado em estudos como elemento de queixas (CARMO, 2014; MENDES et al., 2012; SILVA et al., 2016) e que a alta exigência por produtividade atribui impacto negativo na saúde do trabalhador. 
Vários aspectos listados na organização do trabalho podem gerar doenças ocupacionais inclusive essas questões poderiam ser elucidadas no texto da NR-17. Está evidente que os anexos, mais atuais, incluem itens que poderiam ser seguidos pelo texto principal.

\section{Complementações e contribuições}

Outros referenciais citados na NR-17 são os regulamentos técnicos do Ministério da Saúde e Agência Nacional de Vigilância Sanitária, incluindo a observação "ou outra que venha a substituir" (item 4.3 b anexo 2), assim é possível utilizar uma nova referência.

Recentemente, estudos apontam novos vínculos entre doenças e atividades desenvolvidas no trabalho como exemplo a síndrome visual computacional que pode acometer operadores de teleatendimento (SA; FERREIRA JUNIOR; ROCHA, 2012), indicando a necessidade de revisão constante dos riscos apresentados nos ambientes de trabalho. Confirmando, Souza(2012) observou comprometimento da visão em trabalhadores e especialistas de um centro integrado de saúde, os quais apontaram também como riscos a ventilação e a temperatura inadequadas, além do espaço insuficiente para pessoas e equipamentos.

A preocupação em evitar problemas vocais é evidenciada no anexo 2 (item 8.2.1) por meio de medidas a serem implantadas no ambiente de trabalho. Sem dúvida, os trabalhadores de telemarketing apresentam alta demanda da voz e exigência cognitiva além de fatores físicos, organizacionais e ambientais que podem causar problemas vocais (GIRARDI et al., 2017). Um estudo realizado sobre síndrome visual do computador com operadores de teleatendimento identificou que os sintomas estão ligados à organização do trabalho (SA; FERREIRA JUNIOR; ROCHA, 2012). Cabe salientar que as condições de trabalho estão se alterando e novas síndromes estão surgindo.

A ergonomia pode contribuir para a identificação dos riscos biomecânicos, organizacionais e psicossociais, assim como prover diretrizes de prevenção e promoção da qualidade de vida no trabalho. No entanto, a taxa de doenças relacionadas ao trabalho tem aumentado nas últimas décadas (SILVA et al., 2013; TEIXEIRA, 2014) e ações ligadas à ergonomia poderiam contribuir para a redução destes números. Assim, a revisão da legislação é importante necessária para a efetiva contribuição para a segurança e saúde do trabalhador.

A ergonomia quando aplicada também pode trazer resultados econômicos positivos. Isso foi confirmado pelo estudo realizado por Rando Júnior (2013) que avaliou os riscos antes e depois da intervenção ergonômica para diminuir as exigências físicas nos processos de produção de parede de alvenaria, observou a redução no tempo da atividade e a melhoria na qualidade do serviço.

Outro item a ser considerado é a ocupação na qual o trabalhador permanece sentado por longos períodos. Uma vez que as formas, ajustes e apoios da cadeira são essenciais e influenciam a maneira de sentar, a observância do uso correto do mobiliário reduz a fadiga muscular e diminui a carga mecânica na coluna, evitando lombalgias (ABRAHÃO et al., 2009; IIDA; GUIMARÃES, 2016; MARQUES; HALLAL; GONÇALVES, 2010; MORO, 2000). Cabe ressaltar que as lombalgias são capazes de provocar desde uma simples limitação do movimento até a invalidez e aposentadoria precoce (FREITAS et al., 2011).

Sendo assim, é importante que se faça uma releitura do texto da NR-17 quanto aos incentivos e orientações em relação à "sempre" (item 17.3.1) se projetar o posto de trabalho para a postura sentada. No que se refere aos assentos e aos requisitos altura do assento com a estatura do trabalhador e com a atividade que será executada, a borda arredondada que favorece a circulação e o apoio para a região lombar (item 17.3.3)

As variações posturais, por menores que sejam, são imprescindíveis por variarem os graus de contração, a pressão exercida sobre os discos intervertebrais e favorecer a nutrição por difusão dos tecidos (CORLETT, 2006). Nesse sentido, a NR-17 descreve "características de pouca ou nenhuma conformação na base do assento" (item 17.3.3), ou seja, o assento não poderá sofrer alteração ao ponto de envolver e fixar o quadril, impossibilitando as variações posturais durante a atividade ocupacional sentada.

Em estudo com cirurgiões dentistas, a permanência na postura sentada e com esforços adicionais e inadequados gerou alterações osteomusculares nos membros superiores e na coluna vertebral (ALEXANDRE, 2013). Da mesma forma, outra pesquisa realizada em escritório com trabalhadores que fazem uso de computadores e permanecem sentados apresentaram maior esforço biomecânico e DORT (BARBIERI, 2013).

\section{Considerações finais}

Com este estudo verificou-se a extensão da NR-17 deixando claro que sua potencialidade é sua própria existência. Também, foi possível observar que o uso dos parâmetros e da metodologia AET, que inclui a participação do trabalhador, auxiliam os controles por parte das empresas e órgãos fiscalizadores.

Em relação aos pontos frágeis, observou-se: falta de obrigatoriedade e da indicação dos ergonomistas para a elaboração da AET; participação de órgãos públicos instituições de ensino e pesquisas pouco evidentes no texto; itens desatualizados pontuais que merecem ser revistos.

A participação social na elaboração do texto do anexo 2 revelou um texto mais próximo às carências do trabalhador. Assim, é importante ampliar as discussões, sobretudo que se disponha de mais informações para a aplicação correta da ergonomia nos ambientes de trabalho. Além disso, é preciso aumentar a atuação da ergonomia dentro das empresas no Brasil, sempre em concordância com as demais NR.

Nesta linha de pensamento, para estudos futuros é sugerido verificar o conhecimento e entendimento da NR-17 por parte daqueles que atuam diretamente na ergonomia, bem como ampliar estudos ligados à carga cognitiva dos trabalhadores.

A falta de aplicação da NR17, quer seja pelo desconhecimento, insuficiência de fiscalização ou conflito de entendimento, implica em diversos prejuízos, tanto para os trabalhadores quanto para as empresas. 


\section{REFERÊNCIAS}

ABDALLA, D. R. et al. Postural biomechanical risks for nursing workers. Fisioterapia em Movimento, v. 27, n. 3, p. 421-427, set. 2014.

ABRAHÃO, J. I. et al. Introdução à ergonomia: da prática à teoria. 1. ed. São Paulo: Blucher, 2009

ALEXANDRE, M. A. B. DE. Condições de trabalho e desordens musculoesqueléticas relacionadas à coluna vertebral em dentistas. Porto Alegre: Universidade Federal do Rio Grande do Sul - UFRGS, 2013.

ALTOÉ, A. A. M. Condições ergonômicas laborais para os trabalhadores de enfermagem em terapia intensiva: orientações sobre posturas adequadas. Niterói: Universidade Federal Fluminense, 2013.

AQUINO, L. M. DE. Aplicação das normas de segurança contra incêndio no Estado do Rio Grande do Norte: uma proposta de atualização. p. 169, 2015

ARAÚJO, F. M. DE. Avaliação das condições de trabalho do cirurgião em procedimentos eletivos em dois hospitais públicos em São Luís - MA. São Luís: Universidade Federal do Maranhão, 2014.

AZEVEDO, E. R. F. DE. Análise do trabalho e da saúde das mulheres que desempenham a função de limpeza no polo universitário de Volta Redonda. Niterói: Universidade Federal Fluminense, 2015.

BARBIERI, D. F. Estudo de sintomas musculoesqueléticos, fatores de risco e exposição física em trabalhadores de escritório. São Carlos: Universidade Federal de São Carlos, 2013.

BARBOSA, J. S. V. O trabalhar com médicos obstetras. João Pessoa: Universidade Federal da Paraíba, 2016.

BARBOSA, V. A. Avaliação ergonômica da colheita florestal em área com madeira danificada pelo vento. Jerônimo Monteiro: Universidade Federal do Espírito Santo, 2015.

BRAGA, G. W. Estudo da vibração de corpo inteiro em pilotos de helicoptera esquilo AS-350 L1. Guaratinguetá: Universidade Estadual Paulista (UNESP), 2012.

BRASIL. Norma Regulamentadora 17 - Ergonomia.Brasília, 1990. Disponível em: <http://trabalho.gov.br/images/Documentos/SST/NR/NR17.pdf>. Acesso em: 21 mar. 2017

BRASIL. Cartilha do Plano Nacional de Segurança e Saúde no TrabalhoBrasília, Brasil, 2012.

BRITO, K. M. F. DE. Riscos à saúde dos trabalhadores em unidade de alimentação e nutrição de um Hospital Universitário. Natal: Universidade Federal do Rio Grande do Norte, 2015.

BRITTO, P. C. DE. Análise de fatores ergonômicos em atividades de implantação Florestal. Irati: Universidade Estadual do Centro-Oeste, 2012.

CÂNDIDO, P. E. F. Trabalho e saúde mental em policiais militares de Palhoça (SC).
Florianópolis: Universidade Federal Santa Catarina - UFSC, 2013.

CARMO, M. M. DO. Tribunal da cidadania?! Pra quem?!" : Qualidade de vida no trabalho em um órgão do poder judiciário brasileiro. Brasília: Universidade de Brasília, 2014.

CARNEIRO, T. M. Condições de trabalho em enfermagem na unidade de terapia intensiva. Salvador: Universidade Federal da Bahia, 2013.

CARVALHO, C. DA C. S. et al. Condições ergonômicas dos trabalhadores em galpões de frangos de corte durante a fase de aquecimento. Revista Brasileira de Engenharia Agrícola e Ambiental, v. 16, n. 11, p. 1243-1251, nov. 2012.

CORLETT, E. N. Background to sitting at work: research-based requirements for the design of work seats. Ergonomics, v. 49, n. 14, p. 1538-1546, 15 nov. 2006.

ESTEVAM, F. N. DE L. Variáveis ambientais e ergonômicas na operação com microtrator. Fortaleza: Universidade Federal do Ceará, 2015.

ESTEVO, E. Lixo doméstico produzido em Goiânia: a exposição e o impacto na saúde dos coletores. Goiânia: Pontifícia Universidade Católica de Goiás, 2012. FREITAS, K. P. N. et al. Lombalgia ocupacional e a postura sentada: efeitos da cinesioterapia laboral. Revista Dor, v. 12, n. 4, p. 306-313, 2011.

GIRARDI, B. B. et al. Relação entre condições de trabalho e sintomas vocais em operadores de um call center modelo. Audiology - Communication Research, v. 22, n e1738, p. 1-7, 2017.

GONÇALVES, C. DE O.; IGUTI, A. Análise de programas de preservação da audição em quatro indústrias metalúrgicas de Piracicaba, São Paulo, Brasil Program for hearing loss prevention in. Cad. Saúde Pública, 2006.

GUIMARÃES, B. M. DE; AZEVEDO, L. S. DE. Riscos de distúrbios osteomusculares em punhos de trabalhadores de uma indústria de pescados. Fisioterapia em Movimento, v. 26, n. 3, p. 488-489, set. 2013.

HARARI, D. Fatores que influenciam a prevalência de queixas osteomusculares em trabalhadores de diferentes setores de uma indústria. São Paulo: Universidade de São Paulo, set. 2012.

IEA. Definition and Domains of ergonomics. Disponível em: <http://www.iea.cc/ whats/index.html>. Acesso em: 20 fev. 2018.

IIDA, I.; GUIMARÃES, L. B. DE M. Ergonomia: Projeto e produção. 3. ed. São Paulo: Blucher, 2016.

KROEMER, K.; GRANDJEAN, E. Manual de ergonomia: adaptando o trabalho ao homem. 5. ed. Porto Alegre: Bookman, 2005

LANDI, R. S. Avaliação de fatores ergonômicos em atividades de um viveiro florestal. Jerônimo Monteiro: Universidade Federal do Espírito Santo, 2012.

LAVILLE, A. Ergonomia. São Paulo: EPU, Ed da Universidade de São Paulo, 1977.

MACIEL, D. P. et al. Musculoeskeletal disorder related to the work of doctors who perform medical invasive evaluation. Work, v. 41, p. 1860-1863, 2012. 
MAIA, L. R.; RODRIGUES, L. B. Saúde e segurança no ambiente rural: uma análise das condições de trabalho em um setor de ordenha. Ciência Rural, v. 42, n. 6, p. 1134-1139, jun. 2012.

Manual de Aplicação da Norma Regulamentadora 17. 2. ed. Brasília: MTE, SIT, 2002. MARQUES, G. M.; SILVA-JUNIOR, J. S. Síndrome do manguito rotador em trabalhadores de linha de montagem de caminhões. Cadernos Saúde Coletiva, v. 23, n. 3, p. 323-329, set. 2015.

MARQUES, N. R.; HALLAL, C. Z.; GONÇALVES, M. Características biomecânicas, ergonômicas e clínicas da postura sentada: uma revisão. Fisioterapia e Pesquisa, v. 17, n. 3, p. 270-276, set. 2010.

MATOS, I. C. DE. Condições de trabalho e os seus impactos na saúde em uma unidade de produção de imunobiológicos da FIOCRUZ. Rio de Janeiro: Escola Nacional de Saúde Pública Sérgio Arouca, 2016.

MEDEIROS, L. G. R. Análise da atividade das psicólogas de CRAS do vale do SabugiPB. João Pessoa: Universidade Federal da Paraíba - UFPB, 2015.

MENDES, D. P. et al. Do prescrito ao real: a gestão individual e coletiva dos trabalhadores de enfermagem frente ao risco de acidente de trabalho. Gestão \& Produção, v. 19, n. 4, p. 885-892, dez. 2012.

MERINO, E. A. D. Efeitos agudos e crônicos causados pelo manuseio e movimentação de cargas no trabalhador. Florianópolis: Universidade Federal de Santa Catarina - UFSC, 1996.

MIRANDA, C. R.; DIAS, C. R. PPRA/PCMSO: auditoria, inspeção do trabalho e controle social. Cadernos de Saúde Pública, v. 20, n. 1, p. 224-232, fev. 2004.

MONTMOLLIN, M. DE; DARSES, F. A ergonomia. 2. ed. Porto Alegre: Instituto Piaget, 1990.

MORAES, G. A. Normas regulamentadoras comentadas. 6. ed. Rio de Janeiro: Gerenciamento Verde Editora, 2007.

MORO, A. R. P. Análise biomecânica da postura sentada: uma abordagem ergonômica do mobiliário escolar. Santa Maria: Universidade Federal do Rio Grande do Sul - UFRS, 2000.

NOVAES, A. L. T. Colheita de mexilhões cultivados em Santa Catarina: desempenho operacional, ergonomia e prototipagem de um sistema mecanizado. Florianópolis: Universidade Federal de Santa Catarina - UFSC, 2015.

OLIVEIRA, R. L. M. DE. O desempenho da ergonomia na análise de custos humanos em atividades de alto risco: 0 caso do hidrojatista em linhas de pintura na industria pesada. Recife: Universidade Federal de Pernambuco - UFPE, $2015 a$.

OLIVEIRA, J. A. DO N. Avaliação de riscos ergonômicos nos profissionais de enfermagem do serviço de atendimento móvel de urgência - SAMU/Recife. Recife: Universidade Federal de Pernambuco, 2015b.

PERES, C. C. et al. Uma construção social: o anexo da norma brasileira de ergonomia para o trabalho dos operadores de telemarketing. Revista Brasileira de Saúde Ocupacional, v. 31, n. 114, p. 35-46, dez. 2006.
RANDO JÚNIOR, A. M. Interferência das condições ergonômicas na execução de paredes de alvenaria de blocos cerâmicos. Londrina: Universidade Estadual de Londrina, 2013.

RENNÓ, C. DE O. Análise postural da equipe de enfermagem durante o banho no recém-nascido. Rio de Janeiro: Universidade Federal do Estado do Rio de Janeiro, 2012.

ROCHA, L. F. DA; SIMONELLI, A. P. A utilização da análise ergonômica do trabalho como ferramenta do terapeuta ocupacional no estudo da atividade de trabalho de cabeleireiros. Cadernos de Terapia Ocupacional UfsCar, v. 20, n. 3, p. 413-424, 2012

SA, E. C.; FERREIRA JUNIOR, M.; ROCHA, L. E. Risk factors for computer visual syndrome (CVS) among operators of two call centers in São Paulo, Brazil. Work, v. 41, p. 3568-3574, 2012.

SALA, S. M. F. Ergonomia aplicada a ferramentas manuais: o caso da ferramenta manual para descascamento de raízes de mandiocas. Florianópolis: Universidade Federal de Santa Catarina - UFSC, 2015.

SALIBA, T. M. Curso básico de segurança e higiene ocupacional. São Paulo: LTR, 2011. SANTOS, B. D. DOS. Alternativas mitigadoras de riscos ocupacionais no exercício profissional de catadores de materiais recicláveis vinculados à ARENSA, Campina Grande - PB. Campina Grande: Universidade Estadual da Paraíba, 2016.

SHIMANO, S. G. N.; WALSH, I. A. P. DE; FONSECA, M. DE C. R. Assessment of the perception of aerobatic pilots regarding flight activity. Fisioterapia em Movimento, $v$. 28, n. 1, p. 141-148, mar. 2015

SILVA, J. R. M. DA; TEIXEIRA, R. L. Sobrecarga térmica em fábrica de móveis. Floresta e Ambiente, v. 21, n. 4, p. 494-500, dez. 2014.

SILVA, J. R. R. DA et al. Análise ergonômica da tarefa dos enfermeiros das clínicas cirúrgicas da internação do hospital das clínicas da UFPE: um estudo com o uso da termografia digital. 1 Congresso Internacional de Ergonomia aplicada, p. 686-696, dez. 2016.

SILVA, E. E. DE C. M. et al. Ergonomic evaluation of the position of urgency in a mixed health in Natal/Rio Grande do Norte. Revista de Pesquisa: Cuidado é Fundamental Online, v. 5, n. 3, p. 227-234, 2013.

SOUZA, J. A. C. DE; MAZINI FILHO, M. L. Análise ergonômica dos movimentos e posturas dos operadores de checkout em um supermercado localizado na cidade de Cataguases, Minas Gerais. Gestão \& Produção, v. 24, n. 1, p. 123-135, abr. 2017.

SOUZA, M. G. DE. Visão dos trabalhadores acerca das suas condições de trabalho em um centro integrado de saúde. Rio de Janeiro: Universidade do Estado do Rio de Janeiro, 2012.

TEIXEIRA, C. L. Estudo ergonômico do trabalho dos músicos de uma orquestra sinfônica. Campinas: Universidade Estadual de Campinas - UNICAMP, 2014.

VASCONCELOS, F. M. DE et al. Riscos no ambiente de trabalho no setor de panificação: um estudo de caso em duas indústrias de biscoitos. Gestão \& Produção, v. 22, n. 3, p. 565-589, set. 2015. 
VILELA, R. A. DE G. et al. Pressão por produção e produção de riscos: a "maratona" perigosa do corte manual da cana-de-açúcar. Revista Brasileira de Saúde Ocupacional, v. 40, n. 131, p. 30-48, jun. 2015.

WATERS, T.; PUTZ-ANDERSON, V.; GARG, A. Applications manual for the revised NIOSH lifting equation. Cincinnati: National Institute for Occupational Safety and Health Division of Biomedical and Behavioral Science, 1994.

WISNER, A. A inteligência no Trabalho. São Paulo: FUNDACENTRO, 1994.

ZANOL, E. J. Avaliação dos níveis de vibração de corpo inteiro sofridos por motoristas de ônibus urbanos em diferentes tipos de pistas. Porto Alegre: Escola de Engenharia da Universidade Federal do Rio Grande do Sul, 2014. 